\title{
Diagnóstico da deficiência de fósforo em ovinos pela técnica de incorporação de fósforo radioativo nos eritrócitos
}

\author{
Dalton Araujo Antunes ${ }^{(1)}$, Helder Louvandini( ${ }^{(1)}$, José Cleto da Silva Filho ${ }^{(2)}$, Concepta Margaret McManus ${ }^{(1)}$, \\ Bruno Steffano Dallago ${ }^{(1)}$, Bruno de Oliveira Machado ${ }^{(1)}$, Dharana Guedes Mendonça ${ }^{(1)}$ e Patrícia Spoto Correa $^{(1)}$ \\ (1)Universidade de Brasília, Fac. de Agronomia e Medicina Veterinária, Caixa Postal 04508, CEP 70901-970 Brasília, DF. \\ E-mail: dalton.antunes@bol.com.br (2)Universidade Federal de Lavras, Dep. de Zootecnia, Caixa Postal 37, CEP $72000-000$ Lavras, MG. \\ E-mail: cleto@ufla.br
}

\begin{abstract}
Resumo - Este trabalho teve como objetivo avaliar a técnica de incorporação de ${ }^{32} \mathrm{P}$ pelos eritrócitos de ovinos jovens, mantidos em pastejo de Andropogon gayanus, como método de diagnóstico da deficiência de fósforo. Vinte ovinos, com peso vivo inicial de $13,88 \pm 2,51 \mathrm{~kg}$, foram divididos em dois tratamentos de dez animais cada; num dos tratamentos, os animais foram suplementados com $3 \mathrm{~g}$ de $\mathrm{P}$ por animal por dia e, no outro, os animais não receberam suplementação de P. Foram realizadas cinco pesagens dos animais, coletas de sangue e fezes nos

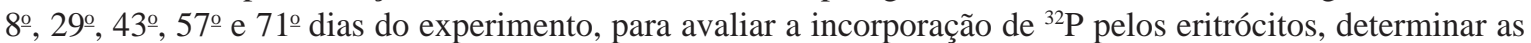
concentrações de $\mathrm{Ca}$, glicose e P no soro e a porcentagem de P nas fezes. Foi encontrada diferença significativa na concentração de Ca no 57ํ dia. Na concentração de glicose, porcentagem de P nas fezes e peso vivo não foram observadas diferenças significativas entre os tratamentos. A partir da segunda coleta, a concentração de $\mathrm{P}$ no soro foi mais elevada e a incorporação de ${ }^{32} \mathrm{P}$ foi menor no grupo de animais suplementados com $\mathrm{P}$. A incorporação de ${ }^{32} \mathrm{P}$ pelos eritrócitos é uma técnica adicional para avaliar o status de $\mathrm{P}$ e identificar sua deficiência subclínica em ovinos jovens.
\end{abstract}

Termos para indexação: Andropogon gayanus, nutrição animal, diluição isotópica, Santa Inês, hemácias.

\section{Phosphorus deficiency diagnosis in sheep using labeled phosphorus uptake by erythrocytes}

\begin{abstract}
This work had the objective of evaluating the method of ${ }^{32} \mathrm{P}$ uptake by the erythrocytes of young sheep, supplemented with phosphorus and kept at pasture of Andropogon gayanus, as a tool for phosphorus deficiency diagnosis. Twenty lambs, initially weighing $13.88 \pm 2.51 \mathrm{~kg}$, were divided in two treatments of ten animals each. In one of them, animals were supplemented with $3 \mathrm{~g}$ of phosphorus per animal per day and, in the other, animals did not receive supplementation of phosphorus. Weighing, and blood and faeces collection were carried out in the $8^{\text {th }}, 29^{\text {th }}, 43^{\text {rd }}, 57^{\text {th }}$ e $71^{\text {st }}$ days of the experiment, to evaluate the incorporation of ${ }^{32} \mathrm{P}$ by the erythrocytes, to determine calcium, glucose and phosphorus concentrations in the serum and percentage of $\mathrm{P}$ in the faeces. Significant difference for the concentration of Ca was found in the $57^{\text {th }}$ day. For the glucose concentration, the percentage of phosphorus in faeces, and the weight, significant differences between the treatments were not observed. From the $29^{\text {th }}$ to the $71^{\text {st }}$ day, the concentration of phosphorus in the serum was higher, and the incorporation of ${ }^{32} \mathrm{P}$ was lower in the group of animals supplemented with phosphorus. The analysis of ${ }^{32} \mathrm{P}$ incorporation by the erythrocytes is an additional tool to evaluate the status of $\mathrm{P}$, with identification of the subclinic deficiency in lambs.
\end{abstract}

Index terms: Andropogon gayanus, animal nutrition, isotopic dilution, hair sheep, haemacytes.

\section{Introdução}

A deficiência de fósforo (P) é uma das mais comuns e economicamente importantes nos animais em pastejo, principalmente em regiões subtropicais e tropicais. As forragens dessas regiões não atendem às necessidades dos ruminantes, e, por isso, deve-se realizar a suplementação desse mineral
(McDowell, 1999), cujo metabolismo está vinculado ao do cálcio.

A carência de $P$, ou seja, a forma clínica da deficiência, pode causar anormalidades nos ossos e dentes, menor crescimento, apetite alterado e fertilidade comprometida, com resultados às vezes irreversíveis, caso haja um diagnóstico tardio (Underwood \& Suttle, 1999). 
Um dos primeiros sintomas da deficiência de P é a redução do consumo de alimentos, situação difícil de ser identificada em animais em pastejo. Os mecanismos fisiológicos envolvidos nesta queda de ingestão indicam redução do P nas vias metabólicas celulares com menor disponibilidade do AMP cíclico, ATP e outras moléculas (Clarke, 1990 citado por Ternouth, 1991).

A deficiência marginal é economicamente mais prejudicial, pois, pela ausência de sinais clínicos, nenhum cuidado é tomado para aumentar o potencial de produtividade dos animais (Ogawa et al., 1989). O desenvolvimento de métodos de detecção e diagnóstico da deficiência subclínica é de grande valor, porque a correção desse distúrbio na fase inicial pode ser feita com dietas mais adequadas.

A utilização apenas do $\mathrm{P}$ plasmático, como método único e confiável na determinação da deficiência de $\mathrm{P}$, tem suas limitações, pois a manutenção dos níveis séricos dentro de valores normais pode ocorrer por meio da reabsorção do tecido ósseo, e também o estresse animal durante a coleta e a manipulação inadequada do sangue podem afetar a análise (McDowell et al., 1986).

Com a finalidade de buscar novas alternativas para melhor caracterização do quadro de deficiência de $\mathrm{P}$ nos ruminantes, Vitti et al. (1988), trabalhando com bovinos, sugerem a análise da incorporação de ${ }^{32} \mathrm{P}$ pelos eritrócitos.

Com o uso desta técnica a determinação da glicose torna-se importante, uma vez que o metabolismo das hemáceas é modulado pelo fosfato inorgânico extracelular, com a presença indispensável da glicose na rota de Embden-Meyerhof. Durante a hipofosfatemia, a geração de ATP pode ser diminuída, em virtude do decréscimo na taxa glicolítica, assim como decresce o substrato da fosforilação do gliceraldeido-3fosfato para 1,3-difosfoglicerato, na etapa da glicose. Baixas concentrações de ATP limitam a conversão de adenosina monofosfato para adenosina difosfato (Wang et al., 1985).

Poucos estudos têm abordado o uso dessa técnica como método de diagnóstico precoce da deficiência de $\mathrm{P}$. Silva Filho (1995) trabalhou com ovinos adultos confinados em gaiolas para estudos de metabolismo e depois Silva Filho et al. (1997) trabalharam com bezerros mantidos a pasto, demonstrando ser esta uma técnica promissora.
O objetivo deste trabalho foi avaliar o método da incorporação de ${ }^{32} \mathrm{P}$ pelos eritrócitos de ovinos jovens mantidos em regime de pastejo, como auxiliar no diagnóstico do status de $\mathrm{P}$.

\section{Material e Métodos}

O experimento foi realizado de dezembro de 2002 a fevereiro de 2003 (período das chuvas), durante 71 dias, na Fazenda Água Limpa, no setor de ovinocultura da Universidade de Brasília, localizado a 15²47' S e 47056' O. O clima da região é do tipo Aw pela classificação de Köppen, com temperatura média anual de $21,1^{\circ} \mathrm{C}$, tendo 16 e $34^{\circ} \mathrm{C}$ como média mínima e máxima, respectivamente. A precipitação anual média é de $1.578,5 \mathrm{~mm}$ e a média anual de umidade relativa, de $68 \%$.

Foram utilizados 20 cordeiros inteiros da raça Santa Inês mestiços, com idade aproximada de quatro meses

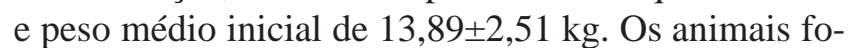
ram divididos em dois tratamentos de dez animais cada. Os cordeiros foram alocados em pastagem de Andropogon gayanus (variedade Planaltina), em uma área aproximada de 2 ha, não ocorrendo nenhum tipo de adubação no decorrer do experimento.

No final da tarde, os dois grupos de animais eram separados em estábulos fechados sem acesso ao pasto, onde pernoitavam e recebiam um concentrado básico composto de $200 \mathrm{~g}$ de farinha de mandioca, $10 \mathrm{~g}$ de uréia e 9,57 g de mistura mineral (0,009 KI; 0,0008 $\mathrm{CoSO}_{4}$; 0,03 $\mathrm{CuSO}_{4} ; 1,61 \mathrm{MgO} ; 3,0 \mathrm{NaCl} ; 0,32 \mathrm{ZnSO}_{4}$; $0,148 \mathrm{MnSO}_{4} ; 0,457 \mathrm{FeSO}_{4} ; 4,0 \mathrm{~S}$ ). Para um dos grupos, foram adicionados ao concentrado 16,66 g por animal de fosfato bicálcico, fornecendo $3 \mathrm{~g}$ de $\mathrm{P}$ por animal por dia (Grupo COMP); o outro grupo permaneceu sem suplementação de P (Grupo SEMP).

O pasto foi coletado nos 6o , 42o e 69o dias depois do início do experimento. As análises bromatológicas dos concentrados e do pasto foram realizadas segundo recomendações da Association of Official Agricultural Chemists (1995) (Tabela 1).

As coletas de sangue e fezes foram realizadas nos

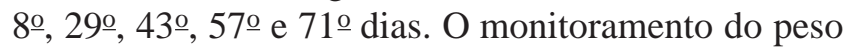
foi realizado nessas datas e no 10 dia. O controle parasitário foi feito semanalmente, por meio da contagem de ovos por grama de fezes, pela técnica de McMaster modificada (Whitlock, 1948). Quando necessário, os animais foram vermifugados com febendazole, conforme recomendação do fabricante. 
O sangue foi coletado diretamente da veia jugular, utilizando dois tubos a vácuo, sendo um com solução de EDTA e outro sem solução. O sangue coletado com EDTA foi utilizado para determinação do hematócrito e da incorporação do ${ }^{32} \mathrm{P}$ pelos eritrócitos. O sangue no tubo sem solução de EDTA foi utilizado para obtenção do soro que foi armazenado a $-20^{\circ} \mathrm{C}$ para determinação das concentrações de $\mathrm{P}$, Ca e glicose.

Em um tubo de ensaio de polietileno com capacidade de $2 \mathrm{~mL}$, foi preparado $1 \mathrm{~mL}$ de solução composta de $\mathrm{NaCl}$ a $0,85 \%$, adicionando-se $3,7 \times 10^{6} \mathrm{~Bq}$ de ${ }^{32} \mathrm{P}$ na forma de $\mathrm{Na}_{2} \mathrm{HPO}_{4}$ de modo que, para cada $10 \mu \mathrm{L}$ de solução, correspondesse uma atividade de $1,85 \times 10^{3} \mathrm{~Bq}$. A incorporação de $\mathrm{P}$ coincidiu com as datas das coletas de sangue, totalizando cinco incorporações.

Na incorporação de ${ }^{32} \mathrm{P}$ pelos eritrócitos, foram utilizados três tubos de ensaio de polietileno, dois como replicatas por amostra e o terceiro como o controle. Em cada tubo foi colocado $1 \mathrm{~mL}$ de sangue, $10 \mu \mathrm{L}$ de solução de ${ }^{32} \mathrm{P}, 10 \mu \mathrm{L}$ de glicose e $10 \mu \mathrm{L}$ de solução de $\mathrm{NaCl}$ a $0,85 \%$, exceto no controle, onde foram adicionados $10 \mu \mathrm{L}$ de $\mathrm{KCN}$ a $10 \%$, para anular a atividade dos eritrócitos. Posteriormente, todos foram levados para incubadora a $38^{\circ} \mathrm{C}$, com atmosfera de $95 \%$ de $\mathrm{O}_{2}$ e $5 \%$ de $\mathrm{CO}_{2}$, durante três horas. Logo em seguida foram acondicionados em uma câmara fria com temperatura aproximada de $5^{\circ} \mathrm{C}$, por 15 minutos, para interromper o metabolismo das hemácias. Depois desse período, $0,5 \mathrm{~mL}$ de sangue do tubo de ensaio foi transferido para cadinhos de porcelana, representando o sangue total. Ao sangue remanescente no tubo de ensaio, foi adicionado $1 \mathrm{~mL}$ de solução de $\mathrm{NaCl}$ a $0,85 \%$ e centrifugou-se

Tabela 1. Composição bromatológica dos alimentos fornecidos aos ovinos nos diferentes tratamentos, em g kg-1 de matéria $\operatorname{seca}^{(1)}$.

\begin{tabular}{lrrr}
\hline Componente & Forragem & \multicolumn{2}{c}{ Concentrado } \\
\cline { 3 - 4 } & & COMP & SEMP \\
\hline Matéria seca & 231,0 & 888,5 & 880,1 \\
Proteína bruta & 99,9 & 238,0 & 232,0 \\
Extrato etéreo & 29,3 & 14,8 & 11,1 \\
FDN & 674,0 & 143,5 & 142,7 \\
FDA & 442,1 & 31,5 & 32,6 \\
Cinzas & 61,9 & 8,4 & 2,8 \\
Fósforo & 2,5 & 16,4 & 0,9 \\
\hline
\end{tabular}

(1)COMP: com suplementação de fósforo; SEMP: sem suplementação de fósforo; FDN: fibra em detergente neutro; FDA: fibra em detergente ácido. por seis segundos a 10.000 rpm para sedimentação dos eritrócitos e remoção do sobrenadante. Tal procedimento foi repetido por mais duas vezes, realizando assim a "lavagem dos eritrócitos”, removendo o ${ }^{32} \mathrm{P}$ extracelular. Depois desse processo, os eritrócitos foram transferidos para cadinhos de porcelana.

Todos os cadinhos de porcelana foram levados para mufla, secados por três horas, a $120^{\circ} \mathrm{C}$, e incinerados por oito horas a $550^{\circ} \mathrm{C}$. Em seguida, os cadinhos foram transferidos para chapa aquecida a $200^{\circ} \mathrm{C}$ e digeridos com $\mathrm{H}_{2} \mathrm{SO}_{4} 6 \mathrm{~N}$. O líquido resultante foi transferido para frascos de contagem, para leitura da atividade radioativa por efeito Cerenkov (International Atomic Energy Agency, 1979).

A porcentagem de incorporação de ${ }^{32} \mathrm{P}$ foi calculada de acordo com Burk Junior et al. (1967), por meio da fórmula: (Atividade nos eritrócitos x 100 x 40)/(Atividade no sangue total $x$ volume celular), em que o valor 40 foi utilizado para padronizar o valor do hematócrito.

$\mathrm{Na}$ determinação das concentrações de $\mathrm{P}$, Ca e glicose no soro foram utilizados kits da Labtest Diagnóstica. As concentrações de P inorgânico nas fezes e na dieta foram determinadas utilizando-se amostras de aproximadamente $1 \mathrm{~g}$, secadas a $100^{\circ} \mathrm{C}$ e incineradas a $550^{\circ} \mathrm{C}$ e posteriormente digeridas com ácido clorídrico. Em seguida, as amostras eram filtradas em papel-filtro Whatman (faixa azul) e transferidas para balões volumétricos de $100 \mathrm{~mL}$, sendo o volume completado com água deionizada. A partir deste procedimento, foi realizada a determinação de $\mathrm{P}$ pelo método colorimétrico (Sarruge \& Haag, 1974).

O delineamento experimental utilizado foi o inteiramente casualizado com dois tratamentos (com e sem P na dieta) com dez repetições e cinco medidas repetidas no tempo. Na análise de variância e na determinação da correlação entre as variáveis estudadas, foi utilizado o SAS (SAS Institute, 1996).

\section{Resultados e Discussão}

Durante todo o período experimental, não foram observadas diferenças significativas entre os dois tratamentos, para os valores de peso vivo (Tabela 2). Tal resultado pode ser justificado pelo fato de os ovinos terem permanecido em pastagem com 0,25\% de P, não tendo sido submetidos à deficiência severa deste mineral, ou em virtude de os 71 dias de experimento não terem sido suficientes para comprometer o peso vivo dos borregos sem suplementação. Segundo Winks (1990), 
deficiência grave de $\mathrm{P}$ pode ser encontrada em animais mantidos em pastagem com $0,15 \%$ de $\mathrm{P}$, com menor consumo de matéria seca e menor ganho de peso.

Em experimento realizado com cordeiros em pastejo, submetidos a três tratamentos: suplementação com mistura mineral comercial $(7,83 \%$ P e $9,50 \% \mathrm{Ca})$, sal comum $(35 \% \mathrm{Na}$ e $25 \% \mathrm{Cl})$ e sem suplementação mineral, Villarroel et al. (1991) verificaram que a suplementação mineral comercial ou de sal comum não apresentaram efeito significativo sobre o desenvolvimento corporal dos animais, demonstrando que, isoladamente, o peso vivo dos cordeiros não é um bom indicativo de deficiência marginal de $P$.

Louvandini et al. (2004), utilizando os mesmos animais deste experimento e avaliando características de carcaça dos ovinos, verificaram que as vísceras abdominais, a 12a costela e o tecido ósseo, nos borregos do grupo COMP, apresentaram-se mais pesados em comparação aos animais do grupo SEMP, com tendência de maior massa também do tecido muscular. Verifica-se assim a necessidade da avaliação de outras variáveis, pois a identificação do quadro de deficiência de P nos ovinos, pelo peso vivo, é muito tardia, com comprometimento da qualidade da carcaça, em especial da parte mais valorizada, como o músculo, importante nos animais destinados ao corte, como o ovino deslanado.

Nos teores de glicose sanguínea (Tabela 2), também não foram verificadas diferenças significativas entre o grupo COMP e o grupo SEMP, cujos valores encontraram-se dentro da faixa normal, de 50 a $80 \mathrm{mg}$ por $100 \mathrm{~mL}$, exceto na penúltima coleta do grupo COMP e na última coleta no grupo SEMP, que apresentaram valores inferiores. Segundo Silva Filho et al. (1997), em trabalho realizado com bovinos submetidos a pasto por seis semanas sem suplementação (Fase 1) e mais seis semanas com suplementação mineral comercial contendo 6\% de $\mathrm{P}$ (Fase 2), o teor de glicose no plasma elevou-se na fase 2 em decorrência da maior concentração de P inorgânico no plasma, influenciando o metabolismo energético destes animais. No entanto, neste trabalho tal situação não se confirmou. A variação entre indivíduos foi muito grande, comprovada pelos desvios-padrão observados, o que tornou difícil inferir confiavelmente sobre essa variável.

Os valores de Ca observados nos dois grupos (Tabela 2) ficaram próximos da faixa considerada normal, de 9 a $12 \mathrm{mg}$ por $100 \mathrm{~mL}$ (McDowell, 1992), com valores numéricos maiores a partir da segunda coleta para o grupo SEMP, com diferença significativa no 570 dia. Segundo Underwood \& Suttle (1999), normalmente a deficiência de $\mathrm{P}$ vem acompanhada de hirpercalcemia, inibindo a secreção do paratormônio, o que sugere a existência de específico e eficiente mecanismo de controle do metabolismo de $\mathrm{P}$, em ruminantes.

O grupo que recebeu suplementação de $\mathrm{P}$ apresentou valores de $\mathrm{P}$ plasmático significativamente superiores em relação ao sem $\mathrm{P}$ (Figura 1), a partir da segunda coleta. A primeira coleta realizada com oito dias não apresentou diferença significativa, provavelmente em virtude do curto período de exposição à dieta carente. Apesar de o teor de P no plasma indicar diferença significativa entre os tratamentos - refletindo o fornecido na dieta e concordando com Ternouth \& Sevilha (1990), que relataram haver relação linear positiva entre o $\mathrm{P}$ consumido e o P no plasma -, nos dois tratamentos ele encontra-se dentro da faixa normal - 4 a $9 \mathrm{mg}$ por $100 \mathrm{~mL}$ (Thompson Junior, 1978) -, e não representa a deficiência imposta pelo tratamento sem suplementação durante todo o tempo em que foi realizado o experimento. Mais uma vez a explicação encontra-se na busca da homeostase do organismo por meio de controle hormonal em relação à dieta deficiente. Sendo assim, esse

Tabela 2. Médias e desvios-padrão dos valores de peso vivo, glicose e cálcio no soro dos ovinos nos tratamentos com fósforo (COMP) e sem fósforo (SEMP)(1).

\begin{tabular}{|c|c|c|c|c|c|c|}
\hline \multirow{2}{*}{$\begin{array}{c}\text { Dias do } \\
\text { experimento }\end{array}$} & \multicolumn{2}{|c|}{ Peso dos animais $(\mathrm{kg})^{(2)}$} & \multicolumn{2}{|c|}{ Glicose $\left(\mathrm{mg} 100 \mathrm{~mL}^{-1}\right)$} & \multicolumn{2}{|c|}{ Cálcio (mg $100 \mathrm{~mL}^{-1}$ ) } \\
\hline & COMP & SEMP & COMP & SEMP & COMP & SEMP \\
\hline 8 & $15,4 \pm 2,8$ & $15,2 \pm 2,3$ & $69,9 \pm 14,6$ & $75,1 \pm 26,7$ & $11,4 \pm 2,2$ & $10,1 \pm 6,4$ \\
\hline 29 & $16,5 \pm 3,5$ & $16,8 \pm 3,0$ & $84,1 \pm 19,8$ & $90,1 \pm 20,2$ & $9,6 \pm 2,8$ & $11,4 \pm 2,8$ \\
\hline 43 & $18,6 \pm 3,0$ & $17,8 \pm 3,7$ & $49,6 \pm 30,2$ & $68,5 \pm 27,2$ & $13,5 \pm 2,1$ & $13,6 \pm 2,4$ \\
\hline 57 & $18,6 \pm 3,2$ & $19,7 \pm 3,9$ & $45,5 \pm 18,2$ & $51,3 \pm 12,6$ & $11,5 \pm 1,8 \mathrm{a}$ & $14,1 \pm 1,9 b$ \\
\hline 71 & $19,5 \pm 3,5$ & $19,6 \pm 4,3$ & $51,8 \pm 21,1$ & $40,8 \pm 20,3$ & $14,3 \pm 1,7$ & $14,5 \pm 2,2$ \\
\hline
\end{tabular}

${ }^{(1)}$ Médias seguidas por letras diferentes na mesma linha diferem entre si a $5 \%$ de probabilidade pelo teste de Tukey. ${ }^{(2)}$ Com um dia de experimento,

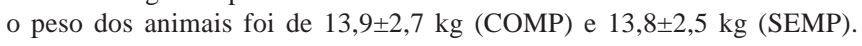


parâmetro sozinho pode levar ao confundimento de animais falso-negativos em situação deficitária, ou, então, há necessidade de reavaliar a faixa tida como normal de P no plasma em ovinos.

As fezes são a principal rota de excreção de $\mathrm{P}$ pelos ruminantes, em que se verifica uma relação positiva entre o P consumido e o P total excretado (Bravo et al., 2003).
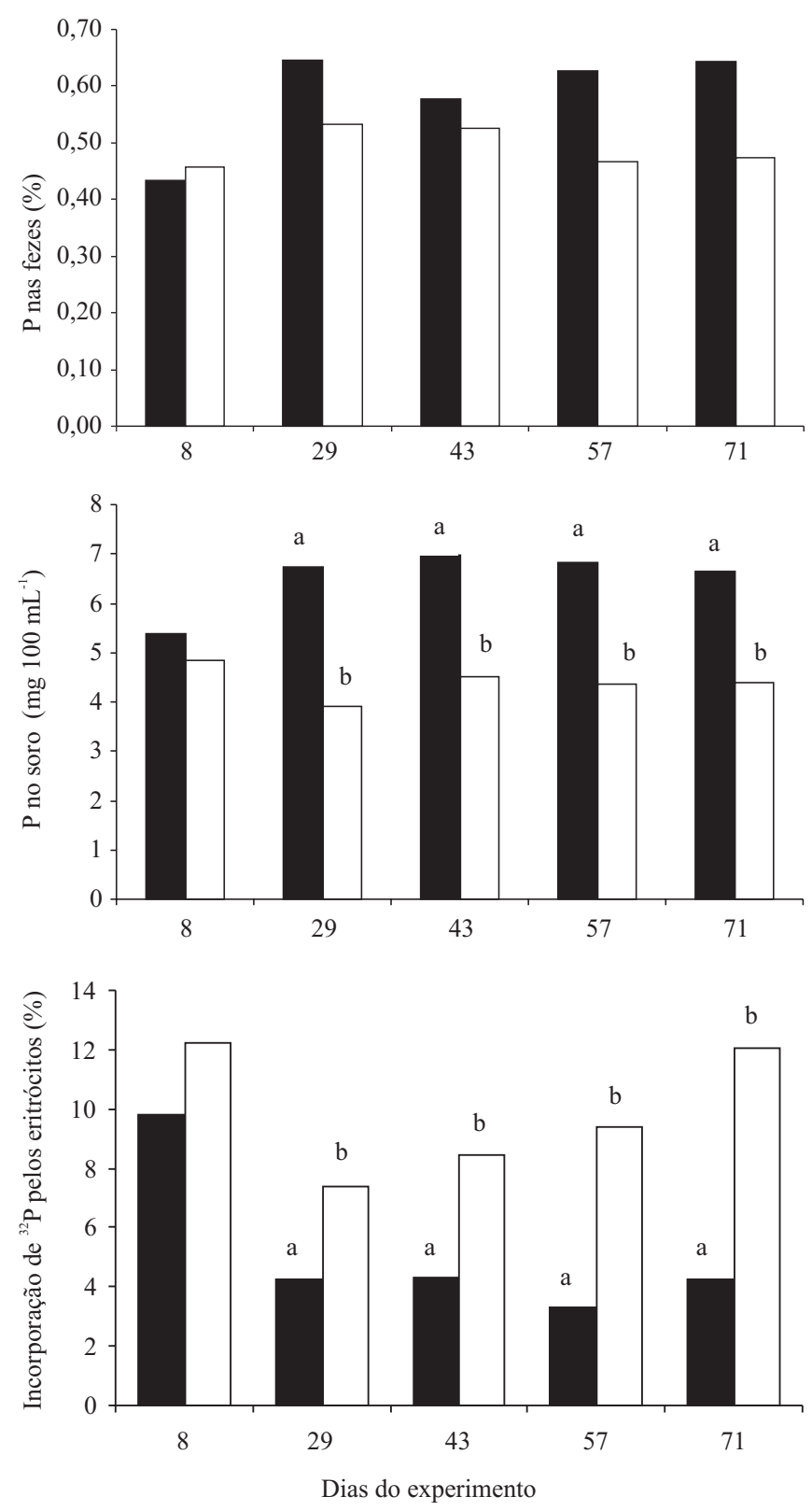

Figura 1. Porcentagem de fósforo nas fezes, concentração de fósforo no soro e incorporação de ${ }^{32} \mathrm{P}$ pelos eritrócitos em ovinos suplementados com P ( $\square$ ) e sem suplementação de P $(\square)$. Médias com letras diferentes diferem entre si a 5\% de probabilidade pelo teste de Tukey.
Desse modo, o P fecal tem sido apontado como mais uma variável importante na inferência do teor de P presente na dieta. No entanto, não foi observada diferença significativa na porcentagem de $\mathrm{P}$ nas fezes entre os grupos COMP e SEMP; apenas valores numéricos maiores no grupo COMP, a partir da coleta do 29o dia. Os valores de $\mathrm{P}$ nas fezes encontrados neste trabalho estão de acordo com resultados observados por Williams et al. (1991) que, apesar de não terem encontrado diferenças significativas entre os tratamentos, relataram teores mais baixos (0,38\%) de $\mathrm{P}$ nas fezes de novilhas mantidas em dieta com baixo teor do elemento $(0,12 \%)$ e índices superiores $(0,49 \%)$ para o grupo mantido em dieta com teor adequado de $\mathrm{P}(0,20 \%)$.

Portilho (2003), além de confirmar a relação linear positiva entre o $\mathrm{P}$ consumido e o $\mathrm{P}$ total excretado nas fezes em ovinos Santa Inês em crescimento, constatou que os animais que não receberam $P$ suplementar na dieta e os que receberam $1,5 \mathrm{~g}$ de $\mathrm{P}$ por animal por dia estavam deficientes, apresentando balanço negativo com valores de retenção de -25,72 e -14,24 mg de P por kg de peso vivo por dia, respectivamente. Essa situação indica que o metabolismo de $\mathrm{P}$ foi mantido por reservas corporais deste elemento, cuja rota de excreção foi as fezes, e que a fração endógena de P encontrada foi significativa, cerca de $27 \%$ do total excretado, mesmo em situação de deficiência.

Outro aspecto que dificulta o uso do P fecal é a necessidade de determinar a excreção total diária, em animais mantidos a pasto, tendo que se trabalhar com a proporção nela presente, e, como um dos primeiros sintomas da deficiência seria a redução de consumo, essa proporção poderia estar aumentada. Nicodemo et al. (2000) observaram que a concentração de $\mathrm{P}$, em amostras de fezes coletadas diretamente do reto de bovinos, não permitiu a detecção precoce de deficiência de P. Deve-se, portanto, ter cautela ao usar o $\mathrm{P}$ nas fezes como método de avaliação do status nutricional deste mineral em ruminantes.

Os animais com suplementação de $\mathrm{P}$ apresentaram valores de incorporação do ${ }^{32} \mathrm{P}$ pelos eritrócitos em torno de 4\% (Figura 1), valor inferior aos observados nos animais sem suplementação, a partir da segunda incorporação. Foi encontrada também uma correlação inversa entre a incorporação de ${ }^{32} \mathrm{P}$ e os teores de $\mathrm{P}$ no plasma $(\mathrm{r}=-0,47, \mathrm{p}<0,0001)$. Silva Filho et al. (1997) também encontraram uma 
correlação negativa entre o $\mathrm{P}$ no plasma e a incorporação $(r=-0,33)$, com maior taxa de incorporação de ${ }^{32} \mathrm{P}$ na fase em que os bezerros não estavam recebendo suplementação de P. A utilização da técnica de incorporação é baseada justamente na premissa de que as hemáceas dos animais com deficiência de $\mathrm{P}$ são mais ávidas à presença do elemento mineral, portanto, os dados encontrados neste trabalho corroboram esta teoria.

Com o decorrer do tempo, os animais que foram submetidos à dieta sem suplementação de $\mathrm{P}$ apresentaram aumento da incorporação em relação à observada na segunda coleta (7\%), indicando ser esta técnica mais sensível que o P no plasma, o qual, embora próximo ao limite mínimo inferior, permaneceu constante frente à restrição alimentar de $\mathrm{P}$ em todo o período experimental. Todavia, mais estudos são necessários para que seja determinado o valor da incorporação indicativo de deficiência. Observa-se também que o $\mathrm{P}$ no plasma e incorporação por eritrócitos são análises complementares.

\section{Conclusão}

A utilização da técnica de incorporação de ${ }^{32} \mathrm{P}$ pelos eritrócitos é válida no diagnóstico da deficiência de $\mathrm{P}$ em ovinos jovens a pasto, com a vantagem de ser não invasiva e complementar à análise de P no plasma.

\section{Referências}

ASSOCIATION OF OFFICIAL AGRICULTURAL CHEMISTS (Arlington, Estados Unidos). Official methods of analysis of AOAC. $16^{\text {th }}$ ed. Arlington, 1995. v.1, p.4-30.

BRAVO, D.; SAUVANT, D.; BOGAERT, C.; MESCHY, F. III: Quantitative aspects of phosphorus excretion in ruminants. Reproduction Nutrition Development, v.43, p.285-300, 2003.

BURK JUNIOR, R.F.; PEARSON, W.N.; WOOD, R.P. $2^{\text {nd }}$; VITERI, F. Blood-selenium levels and in vitro red blood cell uptake of ${ }^{75} \mathrm{Se}$ in kwashiorkor. American Journal of Clinical Nutrition, v.20, p.723733, 1967.

INTERNATIONAL ATOMIC ENERGY AGENCY (Vienna, Áustria). Laboratory training manual on the use of nuclear techniques in animal research. Vienna, 1979. 300p. (Technical report series, 193).

LOUVANDINI, H.; ANTUNES, D.A.; McMANUS, C.M.; DALLAGO, B.S.; MACHADO, B.O. Performance of sheep supplemented with $\mathrm{P}$ using $12^{\text {th }}$ rib analysis. In: ANNUAL
MEETING OF THE EUROPEAN ASSOCIATION FOR ANIMAL PRODUCTION, 55., 2004, Bled, Slovenia. Proceedings. Bled, Slovenia: Wageningen Academic, 2004. v.10, p.121.

McDOWELL, L.R. Minerais para ruminantes sob pastejo em regiões tropicais enfatizando o Brasil. $3^{\text {rd }}$ ed. Gainesville: University of Florida, 1999. 92p.

McDOWELL, L.R. Minerals in animal and human nutrition. San Diego: Academic Press, 1992. 524p.

McDOWELL, L.R.; CONRAD, J.H.; LOOSLI, F.K. Mineral imbalances and their diagnosis in ruminant. In: INTERNATIONAL ATOMIC ENERGY AGENCY (Vienna, Áustria). Nuclear and related techniques in animal production and health. Vienna, 1986. p.521-534.

NICODEMO, M.L.F.; MORAES, S. da S.; ROSA, I.V.; MACEDO, M.C.M.; THIAGO, L.R.L. de S.; ANJOS, C.R. dos. Uso de parâmetros ósseos, plasmáticos e fecais na determinação da deficiência de fósforo em bovinos. Revista Brasileira de Zootecnia, v.29, p.840-847, 2000.

OGAWA, E.; KOBAYASHI, K.; YOSHIURA, N.; MUKAY, J. Hemolytic anemia and red blood cell metabolic disorder attributable to low phosphorus intake in cows. American Journal of Veterinary Research, v.50, p.388-392, 1989.

PORTILHO, F.P. Exigência mínima de fósforo para cordeiros da raça Santa Inês. 2003. 68p. Dissertação (Mestrado) Universidade de Brasília, Brasília.

SARRUGE, J.R.; HAAG, H.P. Análises químicas em plantas. Piracicaba: Esalq, 1974. 56p.

SAS INSTITUTE (Cary, Estados Unidos). SAS system for linear models. Cary, 1996. 211p.

SELAIVE-VILLARROEL, A.B.; CATTANI, J.C.; FIGUEIRÓ, P.R.P.; OLIVEIRA, N.M. de; SILVA, J.G.C. da. Suplementação mineral em cordeiros desmamados. Pesquisa Agropecuária Brasileira, v.26, p.1275-1281, 1991.

SILVA FILHO, J.C. da. Avaliação da incorporação de ${ }^{32} \mathbf{P}$ pelos eritrócitos como método para diagnóstico de deficiência subclínica de fósforo em ruminantes. 1995. 62p. Tese (Doutorado) - Universidade de São Paulo, Piracicaba.

SILVA FILHO, J.C. da; VITTI, D.M.S.S.; LOUVANDINI, H. Metabolismo de fósforo em bovinos: incorporação de fósforo radioativo $\left.{ }^{(32} \mathrm{P}\right)$ pelos eritrócitos. Scientia Agricola, v.54, p.178182, 1997.

TERNOUTH, J.H. The kinetics and requirements of phosphorus in ruminants. In: HO, Y.W.; WONG, H.K.; ABDULLAH, N.; TAJUDDIN, Z.A. (Ed.). Recent advances on the nutrition of herbivores. Kuala Lumpur, Malaysia: Malaysian Society of Animal Production, 1991. p.143-151.

TERNOUTH, J.H.; SEVILLA, C.C. The effects of low levels of dietary phosphorus upon the dry matter intake and metabolism of lambs. Australian Journal of Agricultural Research, v.41, p.175184, 1990. 
THOMPSON JUNIOR, W.R. Phosphorus in animal nutrition. In: POTASH AND PHOSPHATE INSTITUTE. Phosphorus for agriculture: a situation analysis. Atlanta, 1978. p.126-158.

UNDERWOOD, E.J.; SUTTLE, N.F. The mineral nutrition of livestock. $3^{\text {rd }}$ ed. Wallingford: CABI Pub., 1999. 614p.

VITTI, D.M.S.S.; ABDALA, A.L.; SILVA FILHO, J.C. da; AMBROSANO, E.J. Métodos para o diagnóstico da deficiência de fósforo em ruminantes. Pesquisa Agropecuária Brasileira, v.23, p.645-651, 1988.

WANG, X.L.; GALLAGHER, C.H.; McCLURE, T.J.; REEVE, V.E.; CANFIELD, P.J. Bovine post-parturient haemoglobinuria: effect of inorganic phosphate on red cell metabolism. Research in Veterinary Science, v.39, p.333-339, 1985.
WHITLOCK, J.H. Some modifications of the McMaster helminth egg-counting technique and apparatus. Journal of the Council for Scientific and Industrial Research, v.21, p.177180, 1948.

WILLIAMS, S.N.; McDOWELL, L.R.; WARNICK, A.C.; WILKINSON, N.S.; LAWRENCE, L.A. Phosphorus concentrations in blood, milk, feces, bone and selected fluids and tissues of growing heifers as affected by dietary phosphorus. Livestock Research for Rural Development, v.3, p.67-80, 1991.

WINKS, L. Phosphorus and beef-production in northern Australia. II. Responses to phosphorus by ruminants - a review. Tropical Grasslands, v.24, p.140-158, 1990.

Recebido em 9 de julho de 2004 e aprovado em 14 de junho de 2005 